\title{
Curricularização da Extensão nos Cursos de Sistemas de Informação na Universidade Federal de Uberlândia: Um Relato de Experiência
}

\author{
Rafael D. Araújo, Elaine R. F. Paiva, Ana Cláudia Martinez, Jefferson R. Souza ${ }^{1}$ \\ ${ }^{1}$ Faculdade de Computação - Universidade Federal de Uberlândia (UFU) \\ \{rafael.araujo,elaine, anacmartinez,jrsouza\}@ufu.br
}

\begin{abstract}
In the light of the (Brazilian) National Education Plan (PNE 20142024), the National Education Council regulated the guidelines for extension in Brazilian Higher Education in 2018. One of its priority goals is to guarantee a minimum amount of curricular credits for extension in all undergraduate courses in the country. Thus, in addition to reformulating their Pedagogical Political Projects to comply with current legislation, Universities need to ensure that all students comply with the minimum workload of extension activities. Thus, this article presents an experience report on the strategy of reformulating the Information Systems courses at the Federal University of Uberlândia in this context.
\end{abstract}

Resumo. Em face ao Plano Nacional de Educação (PNE 2014-2024), o Conselho Nacional de Educação regulamentou as diretrizes para a extensão na Educação Superior Brasileira em 2018. Uma das metas prioritárias definidas é garantir uma quantidade mínima de créditos curriculares para extensão em todos os cursos de graduação do país. Com isso, além de reformular seus Projetos Político Pedagógico atender à legislação vigente, as Universidades precisam assegurar que todos os estudantes cumpram a carga horária mínima de atividades de extensão. Assim, este artigo apresenta um relato de experiência sobre a estratégia de reformulação dos cursos de Sistemas de Informação da Universidade Federal de Uberlândia nesse contexto.

\section{Introdução}

O Plano Nacional de Educação (PNE 2014-2024), aprovado pela Lei N ${ }^{\circ}$ 13.005/2014 [Brasil 2014], contempla vinte metas nacionais relacionadas à melhoria da educação no Brasil. Dentre elas, a Meta 12 está relacionada com a democratização do acesso à educação superior, com inclusão e qualidade, e se desdobra em 21 estratégias prioritárias para atingir esse objetivo. Dessa maneira, a estratégia 12.7 está relacionada com a obrigatoriedade da inclusão de carga horária curricular nos cursos de graduação e se define:

\footnotetext{
"Assegurar, no mínimo, 10\% do total de créditos curriculares exigidos para a graduação em programas e projetos de extensão universitária, orientando sua ação, prioritariamente, para as áreas de grande pertinência social”.
}

Em 2018, a Câmara de Educação Superior do Conselho Nacional de Educação do Ministério da Educação aprovou, por meio de Resolução, as Diretrizes para a Extensão na Educação Superior Brasileira [Brasil/MEC 2018] que contempla, em seu Art. $4^{\circ}$, o cumprimento da estratégia 12.7 definida no PNE 2014-2024. O prazo dado para 
as instituições de ensino superior implantar tais diretrizes foi de até 3 anos, que seria finalizado em dezembro de 2021, mas estendido em um ano em decorrência pandemia da COVID-19 [Brasil/MEC 2020].

Assim, todos os cursos de graduação no Brasil devem reformular seus Projetos Pedagógicos de Curso (PPC) para incorporar o mínimo exigido de carga horária de extensão em seus currículos. Em uma análise exploratória do PPC dos cursos de Bacharelado em Sistemas de Informação (BSI) das instituições públicas de ensino superior, foi possível perceber que a grande maioria ainda não implantou essa diretriz. Apenas na Faculdade de Computação (FACOM) da Universidade Federal de Uberlândia (UFU) são ofertados dois cursos de BSI, além de outros três cursos presenciais. Os cursos de BSI são de dois campi diferentes, um no campus Santa Mônica em Uberlândia, com oferta anual de 120 vagas no período noturno e um total de $3.000 \mathrm{~h}$, e o outro no campus Monte Carmelo, com oferta anual de 70 vagas em período integral com $3.230 \mathrm{~h}$ totais, juntos com uma oferta de 190 vagas anuais. Apesar dos dois cursos ainda não terem efetivado a implantação da diretriz, ambos possuem propostas de reformulação dos PPC que estão em tramitação na UFU, além de já existirem projetos de extensão conduzidos pelos docentes dos cursos.

Dessa forma, este artigo apresenta um relato de experiência sobre a reformulação dos cursos de BSI da FACOM/UFU para incorporação da carga horária curricular de extensão exigida pelo Ministério da Educação e traz possibilidades de projetos de extensão desenvolvidos no contexto do curso de Sistemas de Informação. Ressalta-se que o foco deste trabalho está na discussão da etapa de construção das estratégias de implantação e que ainda não há indicadores que permitam sua avaliação.

\section{Reformulação do Projeto Pedagógico de Curso}

A Faculdade de Computação da UFU (FACOM/UFU) está passando pelo processo de reformulação dos seus dois cursos de Bacharelado em Sistemas de Informação para atender às diretrizes para extensão na educação superior. A proposta envolve a criação de uma componente curricular denominada Atividade Curricular de Extensão (TEX), regulamentada pelo Conselho da Unidade, que possibilita a participação dos estudantes em projetos de extensão desenvolvidos em comunidades externas à UFU, no Brasil ou no exterior, e relacionados com o perfil de egresso previsto no Plano Político Pedagógico de cada curso.

A carga horária da disciplina corresponde a $10 \%$ da carga horária total do curso, sendo uma disciplina de fluxo contínuo e que possui uma duração máxima medida em termos de semanas. O objetivo de criação da disciplina TEX é que o estudante seja acompanhado durante o desenvolvimento do seu projeto de extensão desde os primeiros períodos do curso e não somente valide um conjunto de certificados obtidos por meio de diferentes participações em atividades de extensão. Uma alternativa seria dividir a componente curricular para atender a essa demanda. No entanto, essa estratégia dificultaria a sua execução em fluxo contínuo e seria necessário definir objetivos de cada componente, pois caso fossem os mesmos, não faria muito sentido ter a divisão. De forma similar, também seria possível pensar em colocar $10 \%$ da carga horária de cada disciplina da grade curricular, porém a execução se tornaria mais complexa.

Os atores envolvidos no componente curricular TEx são: estudante extensionista, coordenador do projeto de extensão, professor da componente curricular, coordenador de extensão da Unidade e o Setor de Extensão da UFU. O estudante extensionista é aquele 
que busca sua inserção em uma atividade de extensão, procurando por projetos desenvolvidos na instituição e quem são os coordenadores responsáveis e se candidata a participar deles. Uma vez que o estudante é aceito para participar em um projeto de extensão, ele se matricula na disciplina TEX. O papel do coordenador do projeto de extensão é coordenar os projetos de extensão na Universidade e introduzir os estudantes em atividades de extensão. O professor da componente curricular TEX orienta o estudante quanto à formalização da TEX, acompanha o andamento do cronograma proposto pelo estudante e aprecia os relatórios e comprovantes de participação apresentados pelos estudantes. A coordenação de extensão da unidade emite pareceres sobre os novos projetos de extensão, além de divulgar e incentivar as atividades de extensão para a comunidade externa.

Uma das grandes dificuldades para a inserção de atividades de extensão na FA$\mathrm{COM} / \mathrm{UFU}$ é seu elevado número de discentes. Considerando um ingresso de 95 alunos semestrais, ou seja, 190 alunos por ano, cumprindo aproximadamente 300 horas de extensão, têm-se um total de 57.000 horas por ano dedicadas à extensão. Além do elevado número de horas dedicados, outros importantes desafios precisam ser enfrentados para a inserção de extensão nos cursos de graduação: $i$ ) Criar projetos de extensão que atendam todo esse volume de horas; ii) Motivar professores a aumentar sua carga de trabalho para coordenar e participar destes projetos; iii) Incentivar alunos a participar destes projetos, em horas extra classe, como por exemplo, finais de semana como forma de atender discentes de cursos noturnos e que utilizam sua jornada diurna para trabalho; iv) Criar um canal de comunicação contínuo com a comunidade para o desenvolvimento de projetos que visem promover a relação Universidade/Sociedade, articulando o ensino e a pesquisa.

\section{Recomendações Práticas}

As atividades de extensão têm como objetivo a comunicação entre Universidade e Sociedade e que estejam vinculadas à formação do estudante, promovendo a troca de conhecimento interdisciplinar, político, social, educacional, cultural, científico e tecnológico. É possível criar ações de extensão na forma de eventos, cursos, minicursos e oficinas, projetos com objetivo específico, programas que agregam projetos inter-relacionados com objetivos comuns ou, ainda, prestação de serviço que necessitam habilidades e conhecimentos de domínio da Universidade.

Assim, é importante que a participação dos estudantes em atividades de extensão aconteça sob a orientação e supervisão de professores/técnicos com projetos aprovados nas devidas instâncias na Universidade, para garantir a característica extensionista vinculada à formação dos estudantes que, ao participar dessas atividades, aprendem a enxergar as necessidades da sociedade e a trabalhar de forma a socializar e democratizar o conhecimento. A área de SI é considerada multidisciplinar e envolve a aplicação da computação em diferentes domínios para solução de problemas e demandas organizacionais e sociais. Essa característica, aliada com a importância estratégica da tecnologia na sociedade e nas organizações contemporâneas, abre a possibilidade de criação de inúmeras atividades extensionistas para aproximação com a comunidade externa à Universidade.

A FACOM/UFU tem atuado com atividades de extensão para a comunidade em diferentes modalidades, dentre as quais destacam-se: (a) cursos: Ensino de Programação e Robótica para alunos do ensino médio e fundamental; Inclusão Digital para Terceira Idade, conduzidos por alunos bolsistas de projetos extensionistas e bolsistas do programa PET; (b) eventos locais e regionais: semanas de estudos que acontecem anualmente, como 
FACOM TechWeek (em Uberlândia) e TechnoMonte (em Monte Carmelo), em que participam estudantes, empresas e a comunidade externa, e "Vem pra Computação" que tem o intuito de informar e esclarecer alunos do ensino médio sobre a área de computação; $(c)$ eventos nacionais e internacionais, como o II Bio-inspired Robotics Day, o Workshop de Visão Computacional (WVC2020), o Congresso Brasileiro de Informática na Educação (CBIE2016), o Simpósio Brasileiro de Sistemas de Informação (SBSI2021), e o Simpósio Brasileiro de Redes de Computadores e Sistemas Distribuídos (SBRC2021); (d) ações em parceria com outras áreas: IV Jornada em Biotecnologia Avançada com a temática "Inteligência Artificial", realizado em Patos de Minas; (e) prestação de serviço para desenvolvimento de sistemas via Empresa Júnior. Desta maneira, os Núcleos Docentes Estruturantes e os Colegiados dos cursos de BSI, juntamente com a Diretoria da FACOM, trabalham em conjunto para estimular o corpo docente a criar novas ações de extensão.

Também é possível enumerar alguns outros exemplos de atividades de extensão na área de SI de outras instituições de ensino superior, como na Universidade de Passo Fundo (UPF) com destaque para dois programas: Programa Conexões Tecnológicas e Programa UniverCidade Educadora e Inteligente UPF, cujo objetivo é estimular o desenvolvimento de soluções tecnológicas criativas. A Universidade Pontifícia Universidade Católica do Rio Grande do Sul (PUCRS) com a oferta de diversos cursos de extensão, dentre eles: "Management 3.0: Práticas de Gestão para Empresas do Século 21" e "Análise de Negócios no Mundo da TI". A Universidade Federal do Paraná (UFPR) realizou o projeto: "Prevenção ao Aliciamento de Crianças e Adolescentes", propondo ações que contribuem para a prevenção do assédio via tecnologia, a partir de orientações quanto ao uso de sistemas de Tecnologia de Informação (TI).

\section{Considerações Finais}

Este artigo apresentou um relato de experiência da estratégia de reformulação dos cursos de BSI da Universidade Federal de Uberlândia para atender à legislação vigente acerca da curricularização da extensão nos cursos de graduação do país. Apesar de ser um eixo obrigatoriamente já explorado pelas Universidades, agora se faz necessário garantir um mínimo de carga horária para essas atividades durante a formação dos estudantes. A área de Sistemas de Informação tem um grande potencial para exploração de atividades de extensão para aproximar a Universidade da comunidade externa e propiciar uma formação ainda mais humanística e com viés social aos estudantes dessa área. Dessa forma, este trabalho apresentou estratégias de extensão comumente abordadas nesse contexto e abre a discussão sobre as potencialidades de extensão universitária em SI ainda não exploradas.

\section{Referências}

Brasil (2014). Plano Nacional de Educação - Lei No 13.005/2014. Diário Oficial da União. Disponível em: http://www.planalto.gov.br/ccivil_03/ _ato2011-2014/2014/lei/113005.htm.

Brasil/MEC (2018). Resolução No 7, de 18 de dezembro de 2018. Diário Oficial da União. Disponível em: https: //www.in.gov.br/materia/-/asset_ publisher/Kujrw0TZC2Mb/content/id/55877808.

Brasil/MEC (2020). PARECER CNE/CES No 498/2020. Diário Oficial da União. Disponível em: https://www.in.gov.br/web/dou/-/ sumula-de-pareceres-278232624. 